\title{
Candidatus Phytoplasma brasiliense associado ao superbrotamento do hibisco (Hibiscus rosa-sinensis L.) no Estado de São Paulo
}

\author{
Eliane Gonçalves da Silva, Ivan Paulo Bedendo, Nelson Sidnei Massola Júnior \& Ricardo Ferrari Silva.
}

Departamento de Entomologia, Fitopatologia e Zoologia Agrícola / ESALQ-USP. Caixa Postal 09 / 13418-900 Piracicaba, SP.

Autor para correspondência: Ivan Paulo Bedendo (ipbedend@esalq.usp.br )

Data de chegada: 04/07/2008. Aceito para publicação em: 25/02/2009

\section{RESUMO}

Silva, E.G.; Bedendo, I.P.; Massola Júnior, N.S. \& Silva, R.F.. Candidatus Phytoplasma brasiliense associado ao superbrotamento do hibisco (Hibiscus rosa-sinensis L.) no Estado de São Paulo. Summa Phytopathologica, v.35, n.3, p.234-236, 2009

Plantas de hibisco com superbrotamento e definhamento seguido de morte têm sido observadas nos municípios de São Paulo, Campinas e Piracicaba. Como os sintomas são sugestivos daqueles induzidos por fitoplasmas, o presente trabalho buscou identificar o possível fitoplasma associado com a doença. Assim, 14 plantas sintomáticas de hibisco foram coletadas em Piracicaba (SP) e submetidas ao PCR duplo com os primers P1/Tint-R16F2n/R2 e ao exame em microscópio eletrônico de transmissão. A identificação foi realizada por análise de RFLP com as enzimas de restrição $B f a \mathrm{I}$, DraI, HaeIII, HhaI, HpaII, MboI, MseI, RsaI e TaqI. Testes de transmissão foram conduzidos com enxertia de ramos e uso de Cuscuta subinclusa. Os resultados de nested-PCR revelaram a presença consistente de fitoplasmas em todas as plantas sintomáticas e foram confirmados pela observação de corpúsculos pleomórficos no floema, através da microscopia eletrônica. A análise de RFLP mostrou que o fitoplasma encontrado em hibisco pertence ao grupo $16 \mathrm{SrXV}$, o mesmo grupo do Candidatus Phytoplasma brasiliense. O fitoplasma foi transmitido de planta doente para sadia, tanto pela enxertia como pela $C$. subinclusa, demonstrando ser o agente do superbrotamento do hibisco.

Palavras-chave adicionais: Mollicutes; enfezamento

\section{ABSTRACT}

Silva, E.G.; Bedendo, I.P.; Massola Júnior, N.S. \& Silva, R.F.. Candidatus Phytoplasma brasiliense associated with hibiscus witches' broom in the State of São Paulo-Brazil. Summa Phytopathologica, v.35, n.3, p.234-236, 2009

Ornamental hibiscus have been affected by shoot proliferation and decline followed by death in several cities in São Paulo State, especially São Paulo, Campinas and Piracicaba. As the symptoms are suggestives of those induced by phytoplasmas, the present work aimed to identify the possible phytoplasma associated with the disease. Fourteen symptomatic hibiscus were sampled in Piracicaba, submitted to nested-PCR with the primers $\mathrm{P} 1 / \mathrm{Tint}-\mathrm{R} 16 \mathrm{~F} 2 \mathrm{n} / \mathrm{R} 2$ and processed by transmission electron microscopy. The identification was made by RFLP analyses with the restriction enzymes BfaI, DraI, HaeIII,
HhaI, HpaII, MboI, MseI, RsaI, and TaqI. Transmission assays were performed by grafting and Cuscuta subinclusa. The presence of phytoplasma was always detected by molecular technique and electron microscopy in all samples. The RFLP analyses showed that the phytoplasma belongs to group $16 \mathrm{SrXV}$, the same group of the Candidatus Phytoplasma brasiliense. It was experimentally transmitted by $C$. subinclusa to periwinkle and by grafting to hibiscus in which it reproduced the original symptoms. This indicates that the studied phytoplasma is the causal agent the disease.

Keywords: Mollicutes, stunt

No Brasil, o hibisco (Hibiscus rosa-sinensis L.) é uma espécie muito apreciada no paisagismo. O declínio da planta, por vezes seguido de morte, tem chamado a atenção de leigos, técnicos e pesquisadores, desde quando a doença foi relatada em São Paulo, na década de setenta (8). Na época, através de microscopia eletrônica, a doença foi associada a fitoplasmas. Posteriormente, foi reportada no Estado do Rio de Janeiro e Distrito Federal (6) e o fitoplasma foi identificado como representante padrão para o $16 \mathrm{SrXV}$, um novo grupo de classificação para fitoplasmas, sendo denominado Candidatus Phytoplasma brasiliense (7). Fora do território brasileiro, há relato da associação de fitoplasma com esta doença, na Austrália (2).

$\mathrm{Na}$ área da grande São Paulo e das regiões de Campinas e Piracicaba, a doença tem sido observada com freqüência. É comum, entretanto, a presença de plantas afetadas em logradouros localizados em áreas fora das cidades mencionadas, mostrando que a doença tem distribuição ampla no Estado de São Paulo. Uma vez que, por microscopia eletrônica, a doença já havia sido relacionada a fitoplasma no Estado de São Paulo, porém não havia sido feita sua identificação, este trabalho buscou identificar o fitoplasma associado ao superbrotamento e demonstrar que o mesmo é o agente da doença.

Neste estudo, 14 plantas sintomáticas foram coletadas em logradouros públicos de Piracicaba (SP). As plantas exibiam clorose foliar, superbrotamento de ramos, folhas e flores pequenas, ramos finos, declínio e morte de ramos ou da planta toda.

Para a detecção molecular de fitoplasma, o DNA foi extraído de tecido foliar (4) e usado em duplo PCR, com os primers P1/Tint $\mathrm{R} 16 \mathrm{~F} 2 \mathrm{n} / \mathrm{R} 2$ (1). DNA de tecido foliar de plantas de hibisco sadias foram usadas como controle negativo, enquanto DNA de tecido foliar 


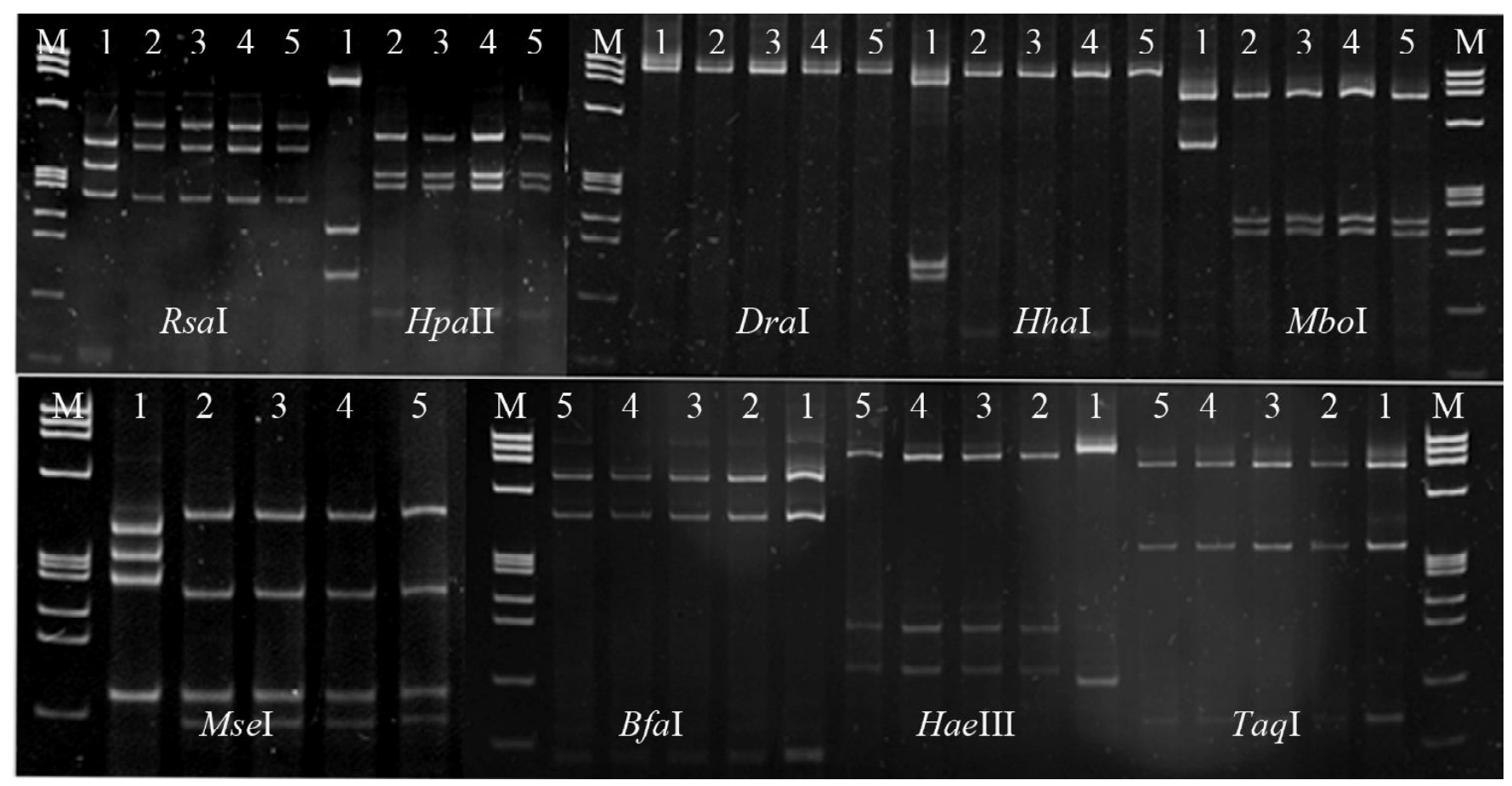

Figura 1. Análise de RFLP mostrando os padrões de restrição apresentados pelo fitoplasma encontrado em plantas de hibisco afetadas pelo enfezamento. A digestão enzimática foi feita a partir de fragmentos de DNA de 1,2 kb amplificados em PCR duplo com os pares de primers P1-Tint /F2n-R2. Coluna M= marcador de massa molecular PhiX 174RF HaeIII; Coluna 1- padrão representado pelo fitoplasma do enfezamento do milho; Colunas 2 a 5- padrões apresentados pelo fitoplasma presente em amostras de plantas sintomáticas de hibisco coletadas em Piracicaba (SP).

de plantas de milho (Zea mays L.) infectadas pelo fitoplasma do enfezamento vermelho serviram como padrão positivo. Os produtos de PCR foram digeridos pelas endonucleases: BfaI, DraI, HaeIII, HhaI, HpaII, MboI, MseI, RsaI e TaqI. Os produtos foram submetidos à eletroforese, sendo os perfis gerados observados em transiluminador de luz ultravioleta. Os padrões de restrição obtidos para o fitoplasma presente nas plantas de hibisco foram comparados aos padrões descritos na literatura $(5 ; 7)$.

Para a detecção dos corpúsculos de fitoplasmas, fragmentos de folhas foram preparados segundo protocolo descrito por Kitajima \& Nome (3) e examinados em microscópio eletrônico de transmissão, pertencente ao Núcleo de Microscopia da ESALQ/ USP.
Teste de transmissão foi feito por enxertia e através da planta parasita Cuscuta subinclusa (Durang \& Hilg.). No primeiro caso, ramos de plantas com sintomas foram enxertados em três mudas sadias de hibisco; no segundo, filamentos de C. subinclusa foram estabelecidos em uma planta doente de hibisco que posteriormente colonizaram quatro plantas sadias de vinca (Catharanthus roseus (L.) G. Don). A transmissão foi avaliada a partir dos 30 dias da enxertia ou estabelecimento da cuscuta, pelo aparecimento de sintomas e pela detecção de fitoplasmas através de duplo PCR.

Os resultados revelaram a presença de fitoplasmas em todas as plantas sintomáticas avaliadas. Fitoplasmas foram detectados pela amplificação de fragmentos genômicos de $1,2 \mathrm{~kb}$, correspondentes ao 16S rDNA. Resultados positivos também foram constatados

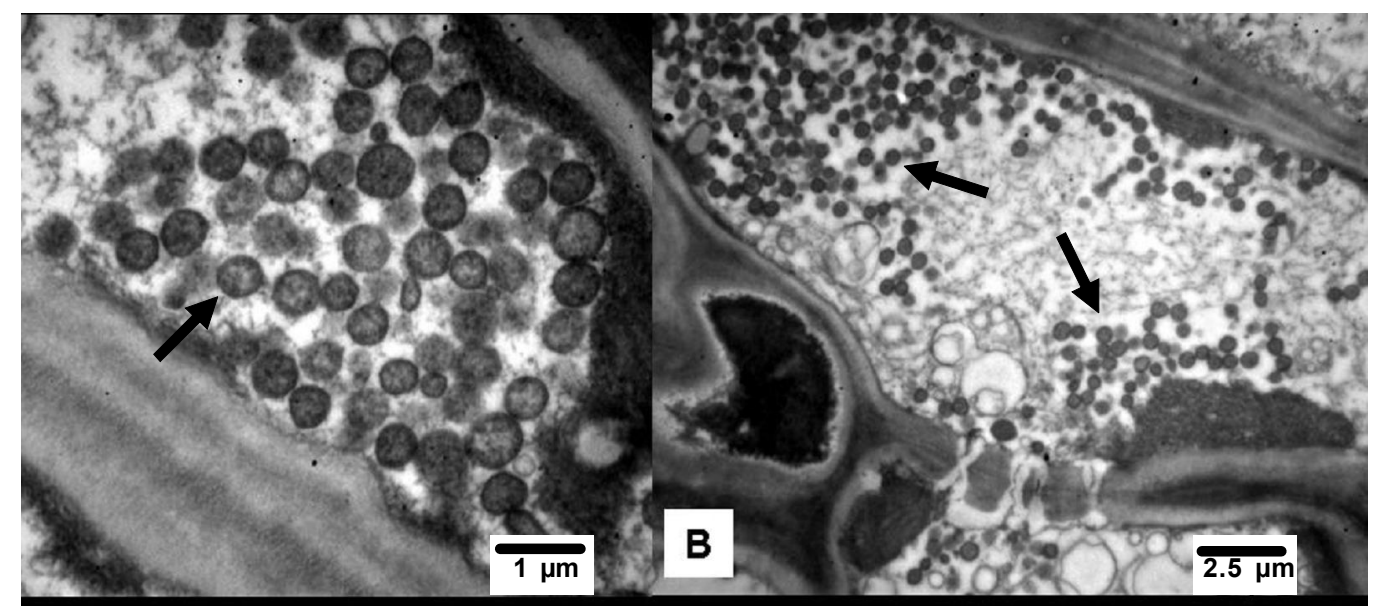

Figura 2. Corpúsculos pleomórficos e arredondados (setas) de fitoplasmas presentes nos vasos de floema de planta de hibisco com sintomas de superbrotamento. 
para o DNA obtido de plantas de milho usadas como padrão. No entanto, nenhuma amplificação ocorreu para DNA extraído de plantas sadias de hibisco, que serviram como padrão negativo (dados não mostrados).

A análise de RFLP mostrou que os padrões de restrição gerados pelas diversas enzimas foram idênticos entre si, para o fitoplasma encontrado nas plantas de hibisco. Por esta razão, foram escolhidos produtos de PCR amplificados a partir de DNA extraído de quatro plantas sintomáticas para representar o fitoplama encontrado nas amostras de hibisco (Figura 1). Os padrões de restrição revelados pelo fitoplasma do hibisco também foram idênticos àqueles relatados na literatura para o fitoplasma representante do grupo $16 \mathrm{SrXV} \mathrm{(5;}$ 7).

Observações ao microscópio eletrônico evidenciaram a ocorrência de corpúsculos pleomórficos de fitoplasmas no floema das plantas afetadas (Figura 2A e B), confirmando a detecção por duplo PCR. Estes corpúsculos não foram visualizados em tecidos de plantas sadias.

A transmissão do fitoplasma foi constatada em todas as plantas sadias de hibisco enxertadas que apresentaram sintomas da doença. Através do uso de C. subinclusa, o fitoplasma também foi transmitido do hibisco para as quatro plantas de vinca. Sintomas de clorose, enfezamento e superbrotamento de ramos foram observados nas plantas de hibisco e vinca, sendo a presença do fitoplasma evidenciada por PCR (dados não mostrados).

Os resultados obtidos no presente trabalho demonstraram a associação entre o superbrotamento e um fitoplasma do $16 \mathrm{SrXV}$. Apesar de fitoplasmas dos grupos 16SrI e 16SrIII predominarem em associação com doenças relatadas no Estado de São Paulo, não foi observada a ocorrência de infecções mistas, mostrando que estes resultados são concordantes com aqueles obtidos em trabalhos conduzidos com plantas de hibisco, no Estado do Rio de Janeiro (7). A transmissão do agente, tanto através de enxertia como de $C$. subinclusa e sua detecção molecular demonstraram que o fitoplasma é o agente causal do superbrotamento do hibisco nas amostras coletadas em Piracicaba(SP).

\section{REFERÊNCIAS BIBLIOGRÁFICAS}

1. Gundersen, D.E.; Lee, I.M. Ultrasensitive detection of phytoplasmas by nested-PCR assays using two universal primer pairs. Phytopathologia Mediterranea, Bologna, v.35, p.144-151, 1996.

2. Hiruki, C. 'Witches'broom of Hibiscus heterophyllus, a mycoplasma disease occuring in Australia. Annals of Phytopathological Society of Japan, Tokio, v.53, p.1-6, 1987.

3. Kitajima, E.W.; Nome, C.F. Microscopia electronica em virologia vegetal. In: Campo, D.M.; Lenardon, S.L. Métodos para detectar patógenos sistêmicos. Córdoba: Instituto Nacional de Tecnologia Agropecuaria , 1999. p.59-86.

4. Lee, I.M; Hammond, R.W.; Davis, R.E. Universal amplification and analysis of pathogen $16 \mathrm{~S}$ rDNA for classification and identification of mycoplasmalike organisms. Phytopathology, Saint Paul, v.83, p.834-842, 1993.

5. Lee, I.M.; Gundersen-Rindal, D.E.; Davis, R.E.; Bartoszik, I.M Revised classification scheme of phytoplasma based on RFLP analyses of $16 \mathrm{~S}$ rDNA and ribosomal protein tgene sequences. International Journal of Systematic Bacteriology, Washington, v. 48, p.1153-1169, 1998.

6. Montano, H.G.; Brioso, P.S.T. Detection of 'Witches'-broom phytoplasmas infecting Hibiscus rosa-sinensis, in Rio de Janeiro, by PCR. In: Reunião da Sociedade Brasileira de Bioquímica e Biologia Molecular. Anais. Rio de Janeiro: Sociedade Brasileira de Bioquímica e Biologia Molecular, 1997, p.74.

7. Montano, H.G.; Davis, R.E.; Dally, E.L.; Hogenhout, S.; Pimentel, J.P.; Brioso, P.S.T. 'Candidatus phytoplasma brasiliense', a new phytoplasma taxon associated with hibiscus witches'broom disease. International Journal of Systematic and Evolutionary Microbiology, Reading, v.51, p.1109-1118, 2001.

8. Vicente, M.; Caner, J.; July, J.R. Corpúsculos do tipo micoplasma em Hibiscus rosa sinensis. Arquivos do Instituto Biológico, São Paulo, v.41, p.53-58, 1974. 